\title{
Study on Chitosan-Lactate Sponges with Oriented Pores as Potential Wound Dressing
}

\author{
Chen Lai ${ }^{1,2}$, Yi Chen ${ }^{3}$, Shujiang Zhang ${ }^{3}$ \\ ${ }^{1}$ Biomedical Engineering Research Center, Beijing University Shenzhen Institution, Shenzhen, China; ${ }^{2}$ Sichuan University, Chengdu \\ China; ${ }^{3}$ The First Affiliated Hospital of Guangzhou Medical College, Guangzhou, China. \\ Email: laichen1110@163.com
}

Received May $21^{\text {st }}, 2013$; revised June $26^{\text {th }}, 2013$; accepted July $8^{\text {th }}, 2013$

Copyright (C) 2013 Chen Lai et al. This is an open access article distributed under the Creative Commons Attribution License, which permits unrestricted use, distribution, and reproduction in any medium, provided the original work is properly cited.

\begin{abstract}
The motive of this work was to provide an inexpensive potential wound dressing using chitosan lactate (LCH) which was synthesized by the grafting lactic acid onto the amino groups in chitosan $(\mathrm{CH})$ without a catalyst. The XRD and ${ }^{13} \mathrm{C}$ NMR results demonstrated that the grafting by lactic acid took place at $\mathrm{C} 2$ site in $\mathrm{CH}$, leading to the destruction of the regularity of the packing in the original $\mathrm{CH}$ chains and formation of the amorphous $\mathrm{CH}$ salts. The unique device was developed in our experiments which could yield an approximately vertical thermal gradient, forming the uniformly vertical pores in LCH sponges. TEM images revealed that both TBA and LCH concentration affected the micro-structure of the sponges, although they worked via different mechanisms. In the water suction experiments, the capillary coefficient Ks was introduced to evaluate the structure-function relationship. The positive or negative influence of LCH, TBA and porosity on Ks clearly stood out when their relationships were plotted graphically. The in vitro biocompatibility of LCH sponges was evaluated. The results obtained indicated that LCH sponges exhibited bio-safety at lower concentration $(25 \%)$ during short time (1 day). However, highly concentrated extraction showed a serious toxic effect on both $\mathrm{HSF}$ and $\mathrm{HaCaT}$ cells. The release kinetics for hydrophilic and hydrophobic drugs with different formulation sponges was determined in in vitro release experiments. The contribution of the drug diffusion, matrix erosion and microstructure of porous materials must be taken into account on the release mechanism. The method and the structure described in present paper provided a starting point for the design and fabrication of a family of chitosan derivatives based porous materials with potentially broad applicability
\end{abstract}

Keywords: Chitosan-Lactate; Sponges; Wound Dressing; Modification

\section{Introduction}

Chitosan is obtained from the partial deacetylation of chitin which is the main component of the exoskeleton of crustaceans, composing of 2-amino-2-deoxy-D-glucose units linked through $\beta$ - $(1 \rightarrow 4)$ bonds. It is also crystalline and shows polymorphism depending on its physical state. Chitosan is a positively charged molecule and soluble in diluted acidic aquous solution. Because of its unique property like antimicrobial activity [1], hemostasis function [2], biodegradability [3], chitosan has attracted scientific interest for various types of biomedical applications. By different method, chitosan can be easily processed into membrane, scaffold, sponge, powder and hydrogel. Numerous works have been done on the modification of chitosan, leading to various derivatives with improved properties. Among these derivatives, chitosan lactate $(\mathrm{LCH})$ is very popular for its great biocompatibil- ity, antibacteria, low toxicity and simple preparation. The ranking of cytotoxicity among these derivatives is chitosan hydrochloride $>$ chitosan glutamate $>$ chitosan lactate [4]. Meanwhile, the ranking of biocompatible was established by various laboratories to be methylpyrrolidone chitosan $>$ chitosan lactate $>$ glycol chitosan $>$ chitosan glutamate $>$ chitosan hydrochloride [5]. Due to the cationic nature of $\mathrm{CH}, \mathrm{LCH}$ can be obtained through simple and green approaches without catalysis. Some researchers' studies suggest that LCH is a safe and efficient gene carrier [6]. It also has been used to develop CPC (calcium phosphate cement) composites with higher strength and increased strain before failure [7]. Controlling the structure of LCH can be done by drying processes in suitable molds. Being produced into porous structures for use in tissue regeneration and drug control release is one of its most promising features. During the freezing proc- 
ess ice crystals nucleate and grow along the lines of thermal gradients. Ice removal by lyophilization generates a porous material. Thereby pore orientation and morphology can be directed by controlling the geometry of the temperature gradients during freezing. Some excipients have the same effects such as tertiary butyl alcohol (TBA) which is a widely used co-solvent and acts as a mass-transfer accelerator in lyophilization processes. It can have great effect on the crystal habit of ice [8] with very low toxicity [9]. It is miscible with water in any proportion and could be removed rapidly and completely by freeze-drying because of its high vapor pressure and high melting point.

In recent years, wound dressing based on chitosan and its derivatives have been commercially available $[4,10]$. Chitosan-based materials can provide a non-protein matrix for $3 \mathrm{D}$ tissue growth and activate macrophages for tumoricidal activity. Previous studies have shown that chitosan-based materials can effectively accelerate wound healing and prevent scar-forming by initiating fibroblast proliferation and collagen deposition [5,11]. Wound repair is a complex process involving many different cell types. Among them, HaCaT (human immortal keratinocytes) and HSF (Human skin fibro-blasts) could present a useful model for the study of potential cytotoxic. Ha$\mathrm{CaT}$ cells are of dermal keratinocyte origin. They are immortalized but not tumorigenic and constitute a direct comparison with normal human epidermal kerationcytes. During the initial inflammatory phase fibroblasts start to enter the wound where they synthesize and later remodel new extracellular matrix. An ideal dressing should offer moist environment at the wound surface, allow gaseous exchange, prevent from microorganisms, absorb exudates and be removed without pain. Despite numerous advantage and unique properties, chitosan and some derivates have a very slow degradation rate, and its molecules degrade in an uncontrollable manner. So it eventually had to be removed from the wound, leading to mechanical damage of newly regenerated tissue and causing pain or discomfort to the patients. Furthermore, adequate ventilation of wound site is very important to avoid wound contamination with microorganisms and accumulation of $\mathrm{CO}_{2}$. However, chitosan based materials have good barrier properties towards oxygen, nitrogen, carbon dioxide and air [12], which hampers their use for wound dressing. Due to the unique structural features of sponges which are soft and flexible with interconnected micropores, they have good fluid absorption capability. If there were unidirectional channel in the sponge, the air and vapor permeability would have been strengthened. One might further hypothesize that the capillarity phenomenon occurring as a consequence of unidirectional channel might allow more rapid absorption of exudates from the wound.
However, only a few research articles have been reported about $\mathrm{LCH}$ with very limited information. In this paper, we present a $\mathrm{LCH}$ sponge with unidirectional channel, carrying antibiotics to enhance their antibacterial activity. Although homo- and copolymers based on Poly lactic acid (PLA) have been widely used in modifying the $\mathrm{CH}$, it exhibits many problems, such as the residues of the catalyst and other organic solvents. Therefore, lactic acid is considered instead of PLA in our experiments. We developed an effective device to obtain steep temperature gradient to form vertical channels in the sponges. For the improved antimicrobial activities, the drug control release mechanism was investigated using penicillin and erythromycin as model drug. The main objective of this research is to discuss the chemical and physical properties, drug release ability and cytotoxicity of LCH sponges for the potential application as inexpensive wound dressing.

\section{Materials and Methods}

\subsection{Materials}

Lactic acid aqueous solution [85\% (w/w)], chitosan (Mw $\sim 389,000$ and $92 \%$ deacetylated), and tertiary butyl alcohol (TBA) were all purchased from Sigma Aldrich Co. (Milwaukee, USA), and were used without further purification. Human skin fibroblasts (HSF) and human immortal keratinocytes (Hacat) were purchased from Kunming Cell Bank of Chinese Academy of Sciences. Penicillin and erythromycin were gifted from Guangzhou Medical College.

\subsection{Preparation of LCH Sponge}

$0.8 \mathrm{~g}$ chitosan and $0.5 \mathrm{~mL}$ lactate acid aqueous solution was dispersed in $40 \mathrm{~mL}$ deionized water. The mixture was stirred overnight at $70^{\circ} \mathrm{C}$, and a clear viscous, light yellow aqueous solution was obtained. The reaction mixture was subjected to dialysis (seamless cellulose tubing with MWCO-14,000 and pore size-50 A) to remove excess lactic acid for 3 days. The dialysis medium was exchanged with fresh water several times. The mixture solution was placed within a refrigerator to freeze at $-78^{\circ} \mathrm{C}$ for 24 hours. The frozen hydrogel was lyophilized within a freeze-dryer for 48 hours. The light yellow and fluffy powders of chitosan lactate $(\mathrm{LCH})$ were fabricated.

As shown in Figure 1, LCH solution (3\% - 10\% w/w) was mixed with TBA $(3 \%-10 \% \mathrm{w} / \mathrm{w})$ by stirring till uniform solution was formed. The mixture was added to the freezing device as shown in Figure 1. The device consisted of two parts: a solution container and a coolant reservoir. The massive copper block in the coolant reservoir acted as the thermal conductor and was continuously cooled by liquid nitrogen $\left(-196^{\circ} \mathrm{C}\right)$. The solution container side is made of polytetrafluoroethylene (PTFE) 


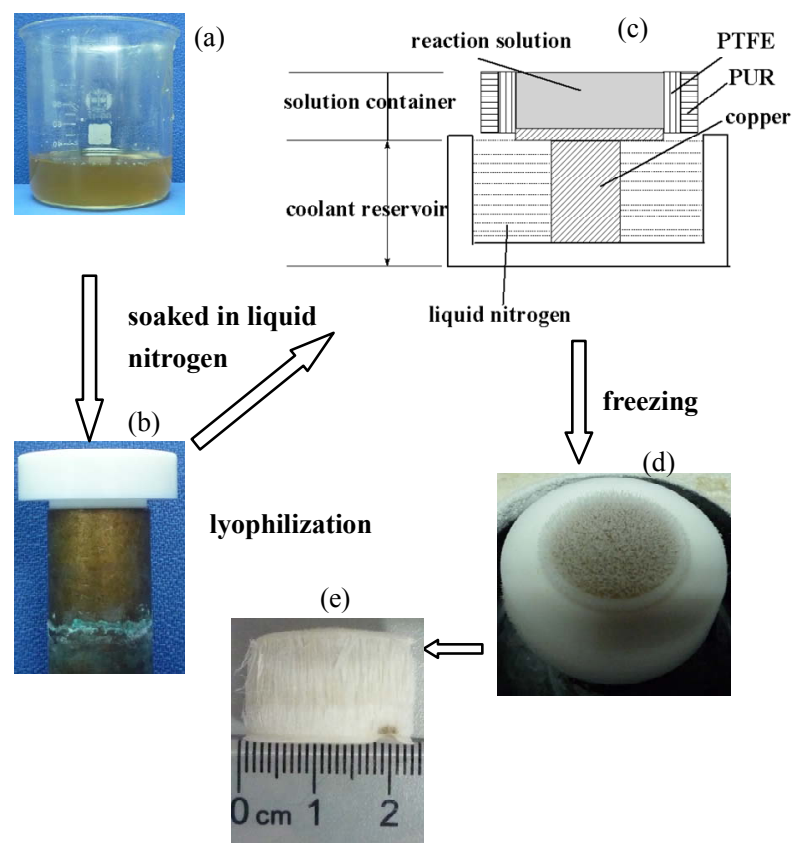

Figure 1. Scheme for preparation process of $\mathrm{LCH}$ sponge. (a) LCH solution; (b) Picture of the solution container. The massive copper block in the coolant reservoir acted as the thermal conductor and was continuously cooled by liquid nitrogen. The solution container side is made of PTFE and surrounded by PUR; (c) Illustration of the vertical temperature controlled device; (d) Picture of a frozen sample placed in a liquid nitrogen bath during the freezing process; (e)The sponge with a size of $2 \mathrm{~cm} \times 1 \mathrm{~cm}$.

and surrounded by polyurethane (PUR) which is the excellent heat preservation materials. The top of the solution container is exposed to the atmosphere at room temperature. This device yields an approximately vertical thermal gradient, leading to the vertical growth of ice crystal. Freezing was accomplished by immersing the device in liquid nitrogen bath. The samples were then lyophilized until dry. After lyophilization, the sponges were further dried at $37^{\circ} \mathrm{C}$ in vacuum drying oven for 24 hours to allow the solvent to be completely evaporated. The round-shaped sponges were stored in desiccators for future use.

\subsection{Contact Angle Measurement and Water Absorption Studies}

Static contact angles of LCH sponges were measured with a contact angle analyzer (OCA 20 Dataphysics, German) using the sessile drop technique. The measurements were carried out at room temperature in air with deionized water as the probe liquid. The average contact angles of three points at different sites of samples were measured. The water adsorbing rate of sponges were determined with direct optical images and video by a camera. Data were analyzed using SCA 20 software.

\subsection{Morphological Characterization and Analysis}

Morphological characterization was conducted using scanning electron microscopy (SEM, 30 XLFEG, Philips, The Netherlands). The samples were prepared by breaking them in liquid nitrogen. Fragments were adhered on a cupreous stub by double-faced adhesive tape and coated with gold and further analyzed.

\subsection{NMR Spectroscopy and X-Ray Diffraction}

Carbon-13 spectra were recorded on a Bruker DRX-400 spectrometer (operating frequency of $400 \mathrm{MHz}$ ). Samples were analysed in $\mathrm{D}_{2} \mathrm{O}$ solution at $60^{\circ} \mathrm{C}$ in $5 \mathrm{~mm}$ o.d. tubes. DDS was used as external standard. ${ }^{13} \mathrm{C}$ NMR were recorded using $90^{\circ}$ pulse, $15,000 \mathrm{~Hz}$ spectral width, 8000 data points, $0.54 \mathrm{~s}$ acquisition time, $3 \mathrm{~s}$ relaxation delay.

$\mathrm{X}$-ray diffraction (XRD) analysis was performed on an X-ray diffractometer (XRD) (X Pert'PRO, PANalytical, The Netherlands) using a flat camera and $40 \mathrm{keV}$ Cuk $\alpha$ $(\mathrm{k}=0.15418 \mathrm{~nm})$ radiation. The samples were scanned from $10^{\circ}$ to $90^{\circ}$ with a scan speed of $10^{\circ} / \mathrm{min}$, respectively.

\subsection{Porosity Determination of Scaffolds}

Porosity of sponge was determined following the method described in the reference [13]. Briefly, ethanol was used as the liquid phase and kept at $25^{\circ} \mathrm{C}$. A bottle filled with ethanol was weighed $\left(W_{1}\right)$. Then a sponge sample weighting WS was immersed into the bottle and weighed $\left(W_{2}\right)$ is the density of ethanol at $25^{\circ} \mathrm{C}$. The size of the cylindrical scaffold including radius $(R)$ and height $(H)$ was measured. The porosity $(P)$ was calculated using the equation as follows:

$$
P=1-\left[\left(W_{1}-W_{2}+W_{s}\right) / \rho\right] /\left(\pi \times R^{2} \times H\right)
$$

\subsection{Cells Culture and Seeding}

HSF and HaCat cells were cultured based on the same pr Cedure. Two kinds of cells were cultured respectively in DMEM (Sigma-Aldrich, USA) $/ 10 \%$ (v/v) FBS (GIBCOFBS-10099-141, Germany), together with supplements of $2.5 \mathrm{mM}$ L-glutamine. The medium was replaced once in every 3 days and the cultures were maintained at $37^{\circ} \mathrm{C}$ in a wet atmosphere containing $5 \% \mathrm{CO}_{2}$. When the cells reached $80 \%-90 \%$ confluence, they were trypsinized with $0.25 \%$ trypsin containing $0.53 \mathrm{mM}$ EDTA (Invitrogen, USA) prior to being used in the experiments.

In all cytoxicity tests performed, culture medium with $0.64 \%$ phenol and standard culture medium were used as positive and negative controls, respectively. Phenol is 
known to have a strong cytotoxic effect leading to extensive cell death, and is commonly used as a positive control for cell death.

To assess the short-term cytotoxicity of the developed sponges, the GB/T16886.7 standard test method was used. The fabricated sponges were sterilized using gamma irradiation from $\mathrm{Co}^{60}$ sources with $25 \mathrm{kGy}$. Sponges were extracted for 24 hours at $37^{\circ} \mathrm{C}$, using standard culture medium as the extracting fluid which was constant and equal to $10 \mathrm{~mL}$. Cells were seeded in 96 wells plates $(\mathrm{n}=10)$, at a density of 3000 cells per well. Cell response was evaluated after 1 day, 2 days, 4 days and 7 days of incubation time at $37^{\circ} \mathrm{C}$, in humidified atmosphere containing $5 \% \mathrm{CO}_{2}$. Because $\mathrm{LCH}$ is water soluble salt of chitosan, immersion in aqueous solution for a long period may result in sponge degradation. Hydrolysis might lead to changes of porous structure of the LCH sponge, therefore the different micro-structure of sponges does not have great effect on the extraction liquid cyctotoxicity.

\subsection{Quantification of Viable Cells (MTT Assay)}

Using MTT (3-(4,5-Dimethylthiazo-a-yl)-2,5-diphenyltetrazoluim bromide) to indirectly reflect viable cell numbers has been widely applied which is based on the fact that metabolically active cells interact with a tetrasolium salt in an MTT reagent to produce a soluble formazan dye. In experiments, MTT was dissolved in PBS at a concentration of $5 \mathrm{mg} / \mathrm{ml}$, sterilized by filtration, and a volume of $20 \mu \mathrm{l}$ added to each well. The solution was then transferred to a cuvette and placed in a Thermospectronic Genesis10 UV-vis spectrophotometer, from which the absorbance at $570 \mathrm{~nm}$ was measured. The viability of the cells cultured with fresh SFM was used as control. The relative cell viability (\%) was calculated according to the following equation based on absorbance at $570 \mathrm{~nm}$ :

$$
\text { relative cell viability }=\left(O D_{s} / O D_{b}\right) \times 100 \%(2)
$$

\subsection{In Vitro Release Studies}

In vitro drug release studies were performed using the USP rotating-basket dissolution apparatus (RC 806, Tianda, China). The receptor medium consisted of 500 $\mathrm{ml}$ of PBS at $\mathrm{pH}$ 7.4. In order to simulate the one-dimensional drug release from the sponges as clinic skin wound dressing, the sponges were constrained in a glass micro-breaker to guarantee that only a single open face with the effective transport area of $2.54 \mathrm{~cm}^{2}$ could contact PBS solution. The sample-carrying micro-breaker was placed in the basket and lower into the PBS solution. The baskets were kept in a thermostated water bath at $37^{\circ} \mathrm{C}$ with temperature fluctuation $\pm 0.1^{\circ} \mathrm{C}$ and were rotated at $100 \mathrm{rpm}$ to eliminate the boundary layer effect. In the controlled release studies, penicillin and erythromycin were chosen as hydrophilic and hydrophobic drug models, respectively. And the drug loading achieved the drug saturated solubility in the LCH sponges. The amount of penicillin and erythromycin was assayed spectrophotometrically at $213 \mathrm{~nm}$ and $241 \mathrm{~nm}$, respectively, using UV spectrophotometer (UV-1800, Shimadzu, Japan). At the sampling time points, a $100 \mu \mathrm{L}$ sample was removed from the release medium and an equivalent volume of PBS solution was replaced to maintain constant volume. In the experiments with erythromycin, $0.25 \mathrm{~mol} / 1 \mathrm{NaOH}$ solution was added into the sample as coloring reagent (1:1 volume ratio) before the spectrophotometer measurements. All studies were performed in triplicate.

For the purpose of comparison, similar experiments were performed in a sealed aluminum vessel. The vessel was then immersed in liquid nitrogen and stored for 24 hours in a freezer at $-78^{\circ} \mathrm{C}$. Subsequently, they were lyophilized in freeze-dryer for 48 hours.

\section{Results and Discussion}

\subsection{Characterization of $L C H$ sponges}

$\mathrm{CH}$ and $\mathrm{LCH}$ were characterized in the solution state by ${ }^{13} \mathrm{C}$ NMR (as shown in Figure 2). As the most notable feature, $\mathrm{C}=\mathrm{O}{ }^{13} \mathrm{C}$ NMR signal of the $\mathrm{LCH}$ appears as triplets, corresponding to the $-\mathrm{COOH}$ in the structure. The signals of $\mathrm{C} 4, \mathrm{C} 5, \mathrm{C} 3, \mathrm{C} 6$ are only slight changed by the formation of $\mathrm{COOH}$, demonstrating that the modification mainly happened on the amino group of $\mathrm{C} 2$ as shown in Figure 3. C1 NMR signal of $\mathrm{LCH}$ is a singlet and the $\mathrm{C} 2$ signal of it also appears as one peak, suggesting that LCH presents 2-fold helical structure [14]. In contrast, the $\mathrm{C} 1$ of $\mathrm{CH}$ is split into a number of sharp peaks, and the $\mathrm{C} 2$ is split into a doublet with the separation of which is 1.64 ppm (see Table 1). Moreover, the signal of C1 at 99.0 ppm are strongly shifted by the modification. This finding

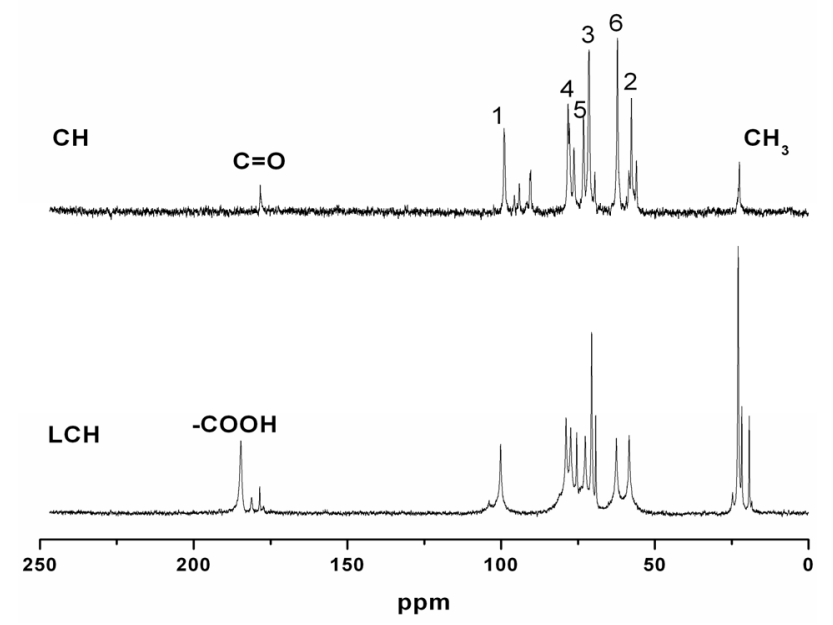

Figure 2. ${ }^{13} \mathrm{C}$ NMR spectra of $\mathrm{LCH}$ and $\mathrm{CH}$. 


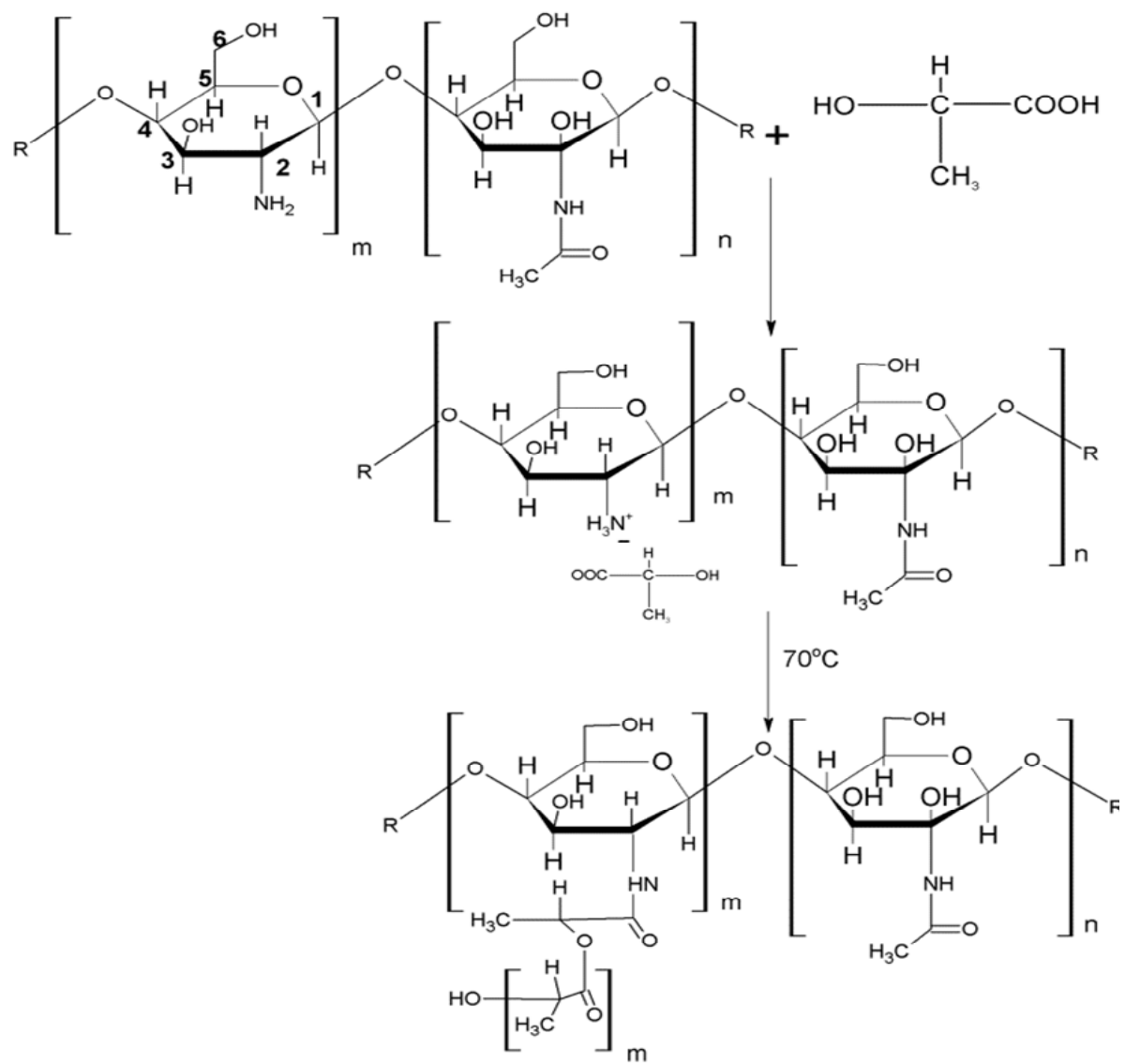

Figure 3. Lactic acid grafted chitosan.

Table $1 .{ }^{13} \mathrm{C}$ chemical shifts of LCH and CH (ppm from TMS).

\begin{tabular}{cccccccccc}
\hline & $\mathrm{C} 1$ & $\mathrm{C} 4$ & $\mathrm{C} 5$ & $\mathrm{C} 3$ & $\mathrm{C} 6$ & $\mathrm{C} 2$ & $\mathrm{C}=\mathrm{O}^{2}$ & $\mathrm{CH}_{3}$ \\
\hline \multirow{2}{*}{$\mathrm{CH}$} & 99.0, & & & & & & & & \\
& 95.6, & 78.2 & 73.2 & 71.4 & 62.2 & 57.62 & & 178.33 & \\
& 94.1, & 76.3 & & 69.5 & & 55.98 & & & \\
\multirow{2}{*}{$\mathrm{LCH}$} & 90.0 & & & & & & & 184.7 & \\
& 105.2 & 78.9 & 72.6 & 70.5 & 62.5 & 58.3 & 181.2 & 22.9 \\
& & 77.4 & & 69.2 & & & 178.5 & 19.3 \\
\hline
\end{tabular}

suggests that a drastic conformational change of $\mathrm{CH}$ might occur during the modification with lactic acid. The NMR spectra are generally insensitive to the change of crystal structure, as a complementary means XRD can further support the NMR results. As shown in Figure 4, the crystallinity of the $\mathrm{LCH}$ is much lower than that of the $\mathrm{CH}$. The peaks having lattice angel $2 \theta=10.3^{\circ}$ and $19.8^{\circ}$ correspond to the equatorial (200) and (020) which are typical fingerprints of semi-crystalline $\mathrm{CH}$. In the LCH diffractogram distinct peak with maxima occurring at the angles $2 \theta=20.4^{\circ}$ and a slight peak at $2 \theta=7.4^{\circ}$ appear. But the peak at $2 \theta=26.4^{\circ}$ disappears. Upon transformation of the $\mathrm{CH}$ into the form of $\mathrm{LCH}$, the crystalline structure changes. The grafting by lactic acid takes place at $\mathrm{C} 2$ which is inside the crystallites, result- ing in the destruction of the regularity of the packing in the original $\mathrm{CH}$ chains and formation of the amorphous $\mathrm{CH}$ salts. $\mathrm{LCH}$ has a more amorphous structure than $\mathrm{CH}$, thus shortening the degradation time of wound dressing. As far as water solubility and biodegradation are concerned, $\mathrm{LCH}$ is found to be superior to $\mathrm{CH}$. Control of sponge pore morphology is critical for controlling cellular colonization rates and organization within an engineering tissue. Figure 5 shows the typical SEM images of the sponges prepared in the sealed aluminum vessel and the vertical temperature controlled device, respectively.

From the images shown above, it is obvious that the freezing process can have a dramatic effect on the microstructure of sponges. The freezing in the sealed alumi- 

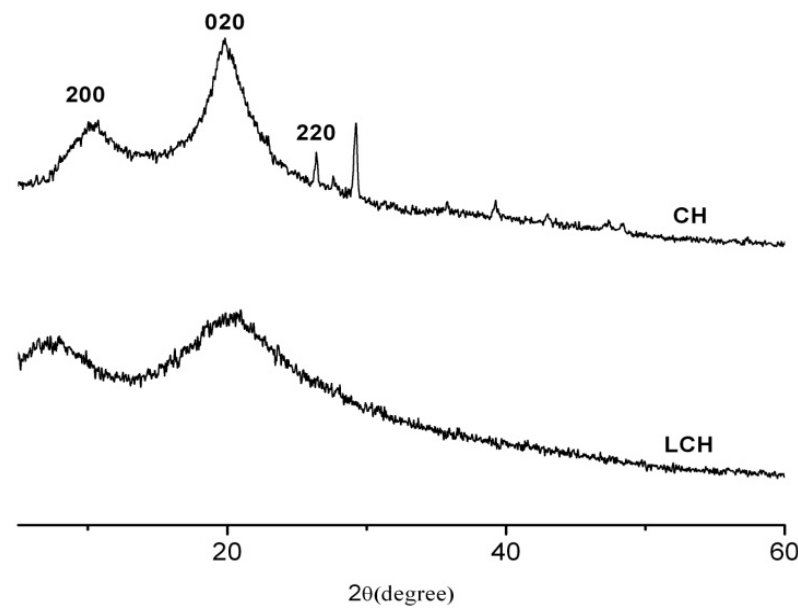

Figure 4. XRD patterns of LCH and CH.

num vessel generate highly connected pores ranging from 15 to $60 \mathrm{~nm}$. In contrast, the samples prepared in special device have vertical oriented channels. This totally different pore structure is most likely the result of the difference in ice growth condition. Under the freezing condition, the solution would be separated into pure ice phase and solvent phase. After ices sublimate during the freeze-drying process, the porous structure duplicated the ice crystal morphology. For the freezing process in aluminum vessel with high thermal conductivity, fast freezing resulted in small ice crystals formation. Freezing started from the metal wall of the device to the center of the solution, this inhomogeneous temperature gradient in the system led to the crystals growth towards all directions. The samples solidified under space-dependent freezing conditions resulted in an inhomogeneous pore structure as shown in Figure 5(a). When solidification operated in the unidirectional freezing devices, ice could grow under a relatively stable temperature gradient. During solidification, the sample was laterally surrounded by a PTFE frame; thus, the isothermal levels within the sample ran parallel to the copper plate. That might result in homogeneous ice-crystal morphology. The pores were directed vertically within the sponge, almost parallel to the heat flow imprinted during the freezing process. While investigating the effects of TBA on the microstructure of sponges, we note that the smooth channel walls appeared significantly more textured with TBA concentration increasing from $3 \%$ to $20 \%$. A number of lyophilization technologies based on the use of TBA have suggested $[6,15]$ that at lower concentration of TBA (3\%) there were enough water molecules to surround TBA molecules, forming stable clathrate hydrates in which water molecules bonded to form an ice-like cage [6].

Water under this condition tended to behave like ice crystal which has highly ordered structure. This produces the elongate, oriented, uniform ice crystals which grow
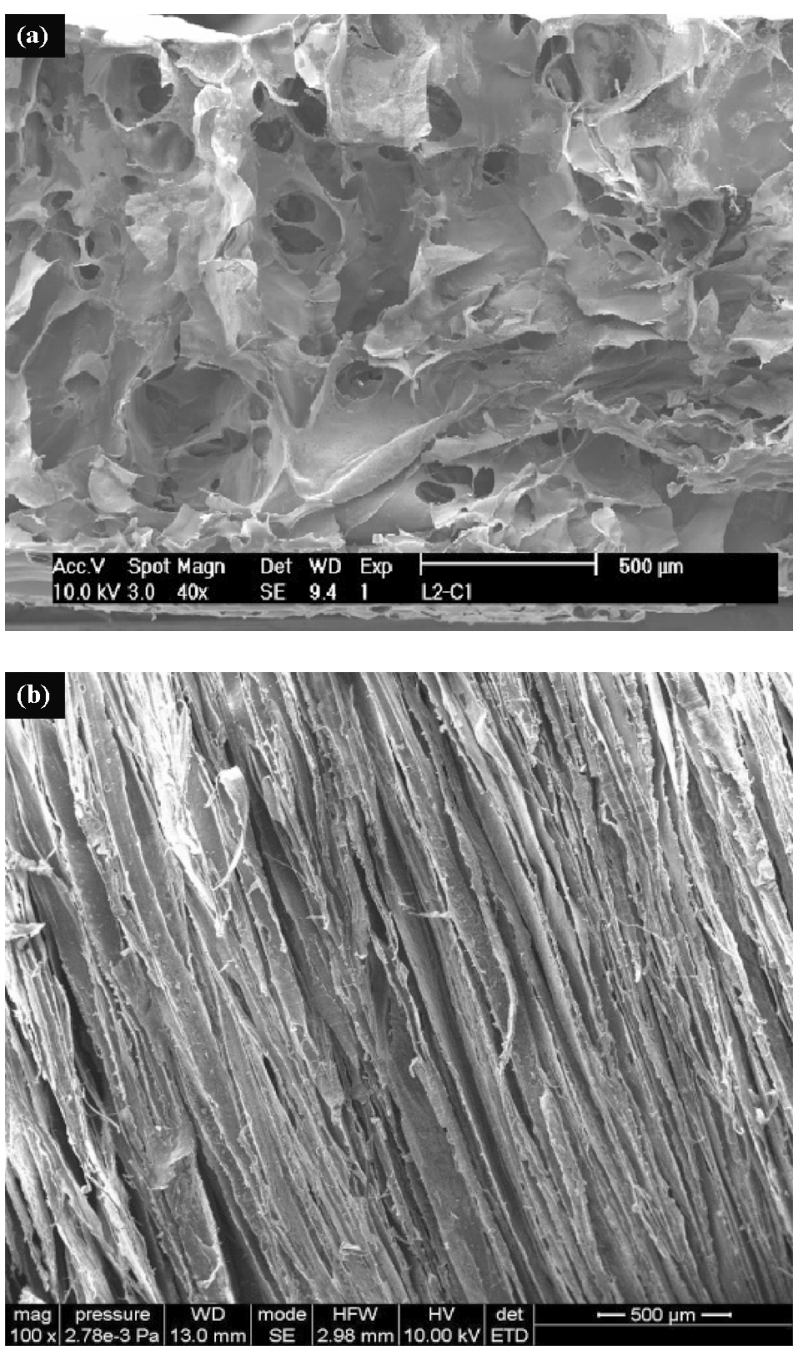

Figure 5. SEM images of LCH sponges prepared under different condition. (a) In sealed aluminum vessel by immersion in liquid nitrogen; (b) In vertical temperature controlled device with TBA.

parallel to the thermal gradient. The micrographs of Figure 6(b) also demonstrate two levels of porosity at the concentration of 5\% TBA. The elongate, oriented microtubule with thicker wall can be observed. On the other side, the surfaces of microtubule walls exhibited many small pores which are arranged in parallel arrays along ridges or grooves in the surface. This two-phase structure is most likely the result of the difference in ice nucleation conditions in the system. With the increasing concentration of TBA, because no enough water molecules left to surround the TBA molecule, there was more opportunity for TBA molecules to self-associate and form dimmers that were connected by hydrogen bonds. These low-density water clusters could not produce ice-like crystals due to their lack of long-range order. Hence, many smaller amorphous ice grains formed at the wall of microtubule like Figure 6(b). The fact that many of smaller ice grains 


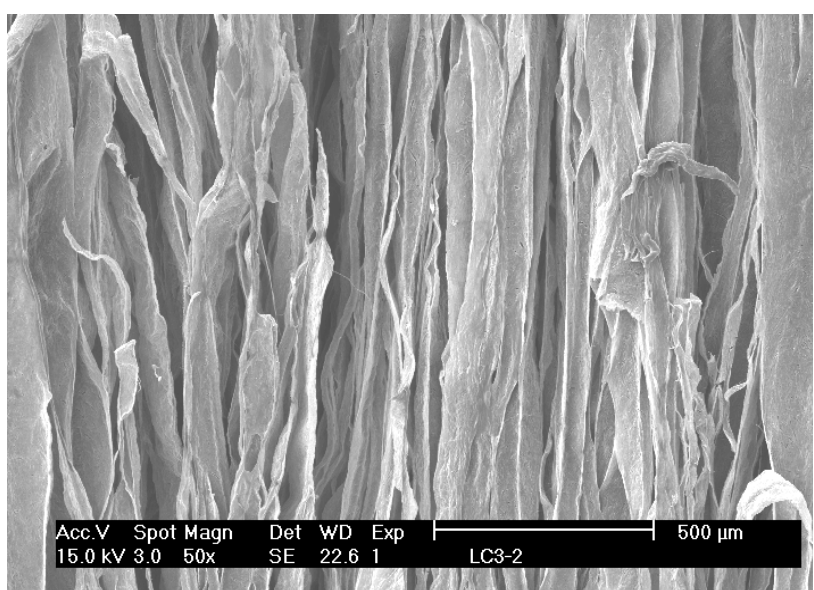

(a)

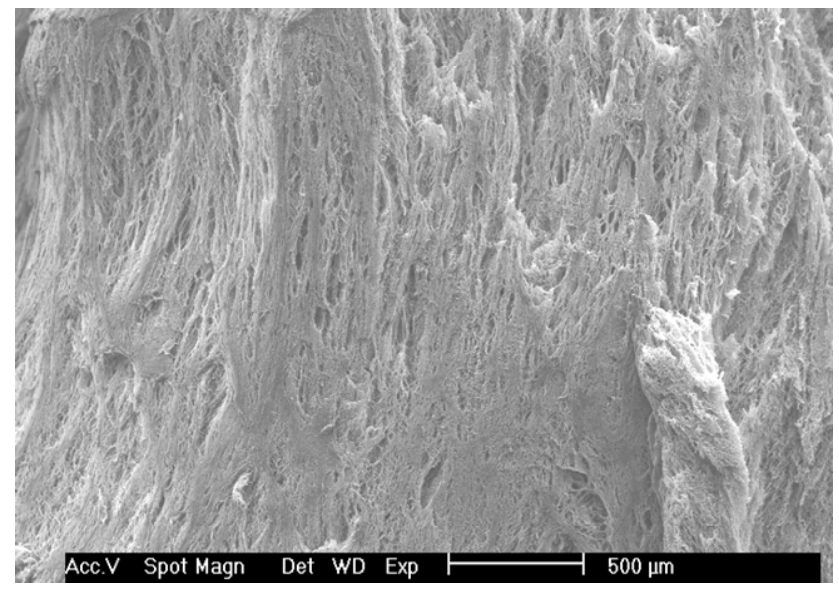

(c)

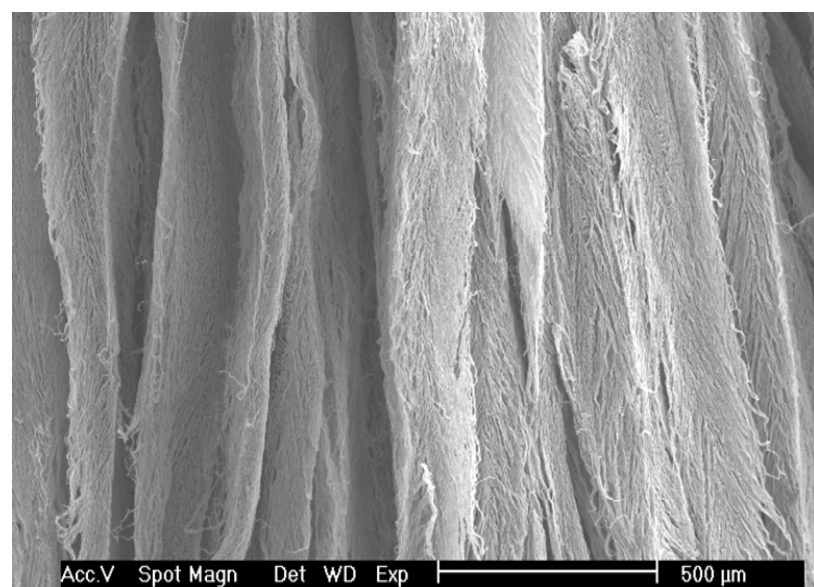

(b)

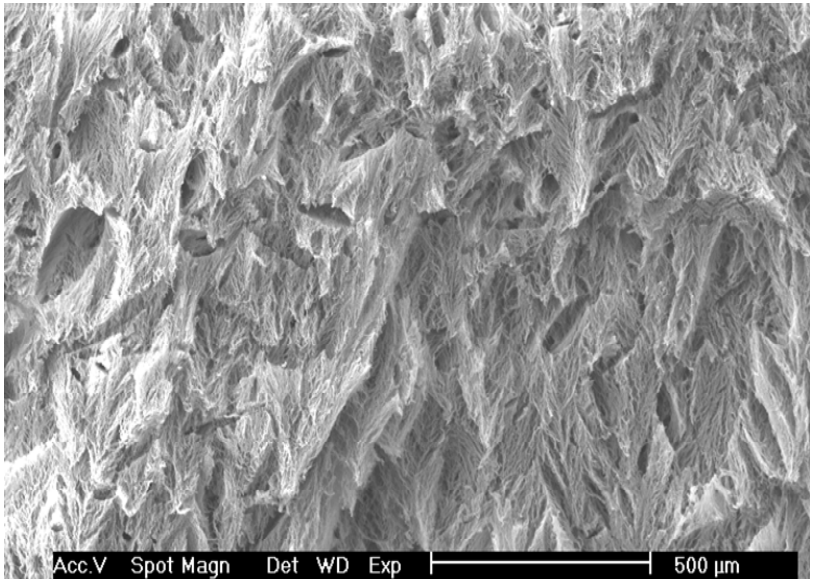

(d)

Figure 6. Dependence of cross-section of spongy microstructure on concentration (w/w) of TBA in solution frozen in the setup with vertical temperature gradient by contact with liquid nitrogen: (a) $3 \%$; (b) $5 \%$; (c) $15 \%$; (d) $20 \%$.

formed at the higher concentration was in agreement with observations reported elsewhere [16,17]. As the increasing of TBA concentration (15\% and $20 \%$ ), the morphology of amorphous ice tended to be irregular, suggesting that TBA could act as effective ice crystal growth modifiers and exert a strong influence on the external morphology and /or crystalline structure of ice. Many small irregular holes were formed, with pleat-shaped tracing of microscopic ice formation as shown in Figures 6(c) and (d). The micromorphologies of channel and even the holes in the walls of the channels inherently affect both the mechanical and solubility properties of the sponges.

\subsection{The Properties as Wound Dressing}

\subsubsection{Water Absorption Behavior}

The absorption of excessive interstitial fluid in the wound bed is critical to wound healing. Excessive moisture inhibits cell proliferation leading to tissue saturation and wound break down. The sponges prepared in our experiment are soft and elastic with uniform vertical pores in which capillarity phenomenon often occurs. Capillarity capacity is not often reported for sponge materials, however, it is a useful parameter to understand the structure-function relationship and the future development of LCH sponges in wound dressing. For various classes of porous material, including paper, powders, rocks and soil, previous studied have shown that the water uptake can be expressed as well-known Washburn Equation [18]

$$
m=K s \times t^{\frac{1}{2}}
$$

where $m$ is the water absorbed by a porous solid per unit of surface area, $t$ means the elapsed time, $K s$ is defined as the capillary coefficient characterizing the quantification of the capillary suction. The equation predicts a linear relation between $m$ and $t^{1 / 2}$ with a slope $K s$.

The suction behavior of each sample is illustrated in Figure 7(a), where the liquid mass absorbed per unit area $(\mathrm{m})$ is plotted versus the square root of the elapsed 


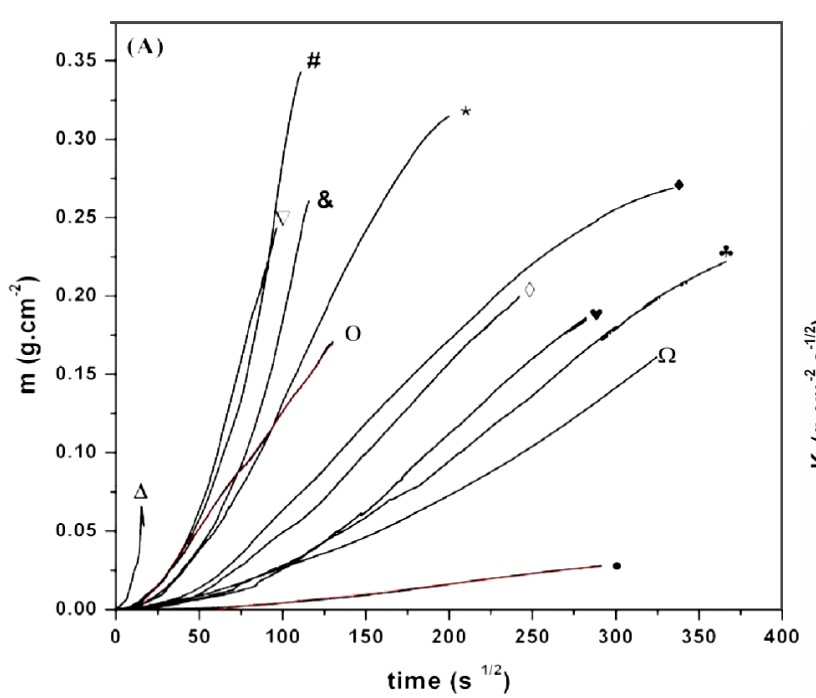

(a)

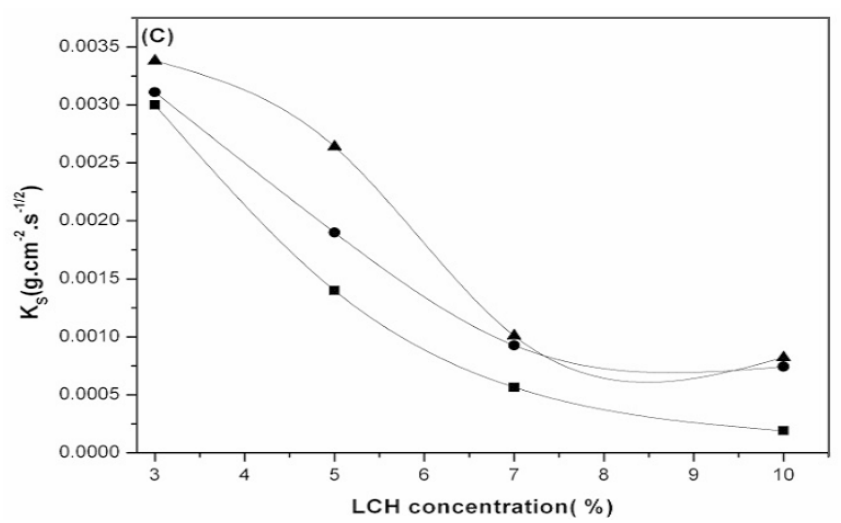

(c)

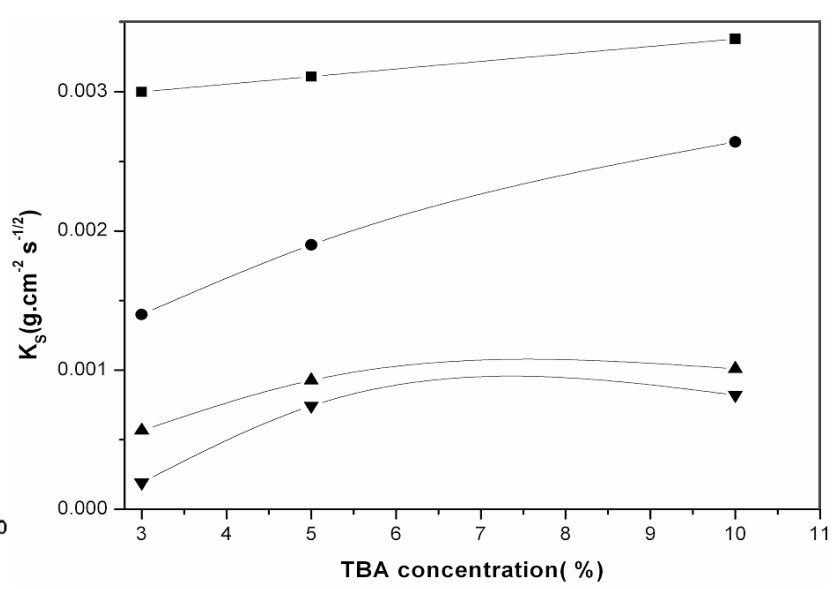

(b)

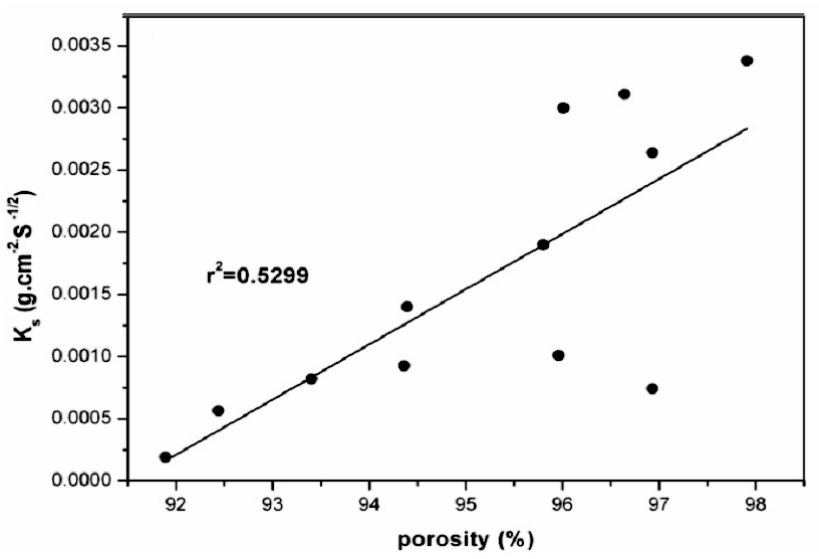

(d)

Figure 7. The water adsorption behavior of samples with various formulations. (a) Water absorption rate of various samples;

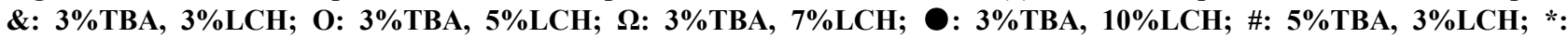
5\% TBA, 5\%LCH; ४: 5\% TBA, 7\%LCH; 5\% 5BA, 10\%LCH; $\triangle:$ 10\%TBA, 3\%LCH; 10\%TBA, 5\%LCH; $\diamond: 10 \%$ TBA, 7\%LCH; ४: 10\% TBA, 10\%LCH; (b) Effect of TBA concentration on Ks; $\square$ : 3\%LCH; O: 5\%LCH; $\triangle$ : 7\%LCH; $\nabla \mathrm{L}$ : 10\%LCH; (c) Effect of LCH concentration on Ks. $\triangle$ : 10\%TBA; O : 5\%TBA; $\square$ : 3\%TBA; (d) Effect of porosity on Ks.

time (t). The samples prepared with lower LCH or TBA concentration present steep slope, indicating the rapid water uptake. The effects of LCH and TBA concentration on the $K s$ are shown in Figures 7(b) and (c). From the results given above, it is obvious that an increase in $\mathrm{LCH}$ concentration results in a decrease of $K s$. In contrast to $\mathrm{LCH}$ tendency, as the concentration of TBA increases, the $K s$ also increases. The fluctuation of $K s$ versus TBA concentration seems to be much flatter compared to those of LCH. Therefore, we believed that the LCH concentration plays a much more influential role than TBA concentration on the suction capacity of the sponges. Several researchers have found evidence that a less dense porous material is able to absorb a higher liquid amount for the same porosity [19]. Although TBA can alter ice crystal growth and hence affect the ice morphology, the change of TBA concentration does not lead to dramatic change in solution viscosity. LCH concentration makes a substantial contribution to the compactness in sponges by influencing the viscosity of the solution. The samples made from high viscosity often exhibit higher strength and less elastic in present experiments. Therefore, the fluctuation in $\mathrm{LCH}$ concentration leads to a dramatic effect on suction capacity. Generally speaking, the suction capacity in porous materials $(K s)$ has a first correspondence with their pore size and amount.To further assess the relationship between $K s$ and porosity, their correlation is presented in Figure $7(\mathbf{d})$. A positive correlation of $K s$ with porosity seems to exist though with a quite low statistical significance $\left(\mathrm{r}^{2}=0.5299\right)$, corroborating that the suction capacity does not depend on the porosity completely in present study. The same porosity 
corresponds to quite different value of $K s$ especially at higher porosity. One possible reason for these results lies in the influence of other parameter on the capillary coefficient as expressed:

$$
K s=C \times(\varepsilon / \lambda) \times r_{0}^{\frac{1}{2}}
$$

where $C$ is a constant corresponding to the liquid, represents the effective porosity (the open porosity actually accessible by the liquid), $r_{0}$ is the median pore size, means the pore tortuosity of the solid which is a nondimensional parameter. One classic definition of tortuousity is often given by Bear [20]. In case of parallel cylindrical capillaries which are perpendicularly arranged with regard to the bed of a liquid it is about 1 . The channels in our experiments are vertical cylindrical capillaries, but the holes in the channel walls make the fluid route more tortuous than theoretical condition. Such fluid movement in present capillary system is hard to reconcile with vertical movement in ideal parallel cylindrical capillary. It is likely that many factors are at play in determining the tortuosity including the $\mathrm{LCH}$, TBA concentration and the freezing behavior, resulting in a more complex dependence of $K s$ on the porosity. Their relationship therefore deviates from linear relationship. However, the capillary behavior of the sponge described in present paper is rather complicated and may deserve a further study.

\subsubsection{Cell Viability}

Figure 8 shows the viability of $\mathrm{HaCaT}$ and $\mathrm{HSF}$ cell after being cultured with the extraction medium, prepared by immersing sponges in it. The effects of $\mathrm{LCH}$ on two kinds of cell viability are found to be time and concentration dependent. At lower concentration extraction $(<25 \%)$, LCH time-dependently inhibited HSF cell proliferation by approximately $88 \%$ ( 2 days) and $86 \%$ (4 days). With increasing concentration $(50 \%-100 \%)$, the incubation time influenced cell viability only marginally. The results suggest that the higher concentration extraction medium from LCH sponges is harmful for the HSF cells. A dramatic increase of cytotoxicity on $\mathrm{HaCaT}$ cells by the increasing $\mathrm{LCH}$ concentration is also observed. At $25 \%$ LCH extraction time-dependently inhibited $\mathrm{HaCaT}$ cell proliferation by approximately $89 \%$ (2 days) and 94\% (4 days). Higher concentration led to a significant decrease in viable cells, but it seemed that the $50 \% \mathrm{LCH}$ extraction was much safer for $\mathrm{HaCaT}$ cells than HSF cells. As shown, the viability of the $\mathrm{HaCaT}$ cells cultured in the $50 \% \mathrm{LCH}$ extraction medium is $93 \%$ after 1 day incubation, while only $50 \%$ HSF cells viability is obtained by the same treatment. According to the United States pharmacopoeia about toxicity classification [21], $50 \%$ concentration of LCH extraction shows cytotoxicity

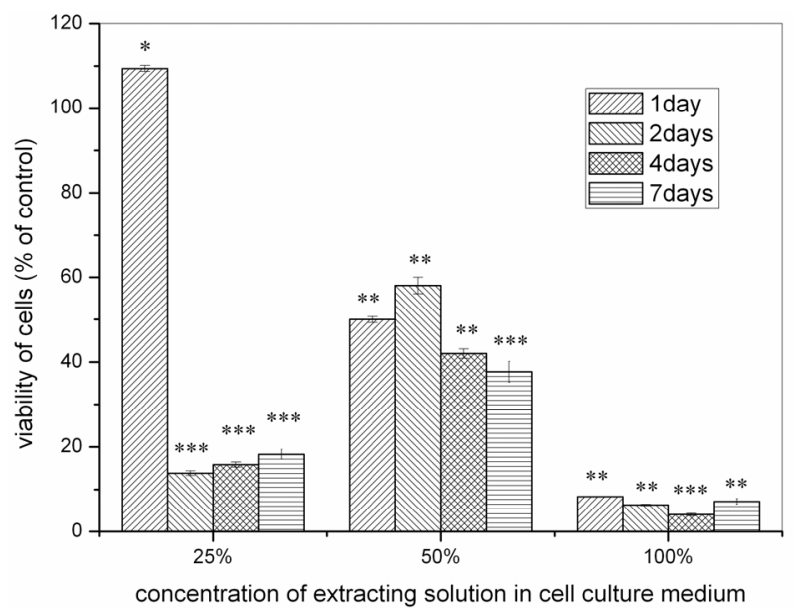

(a)

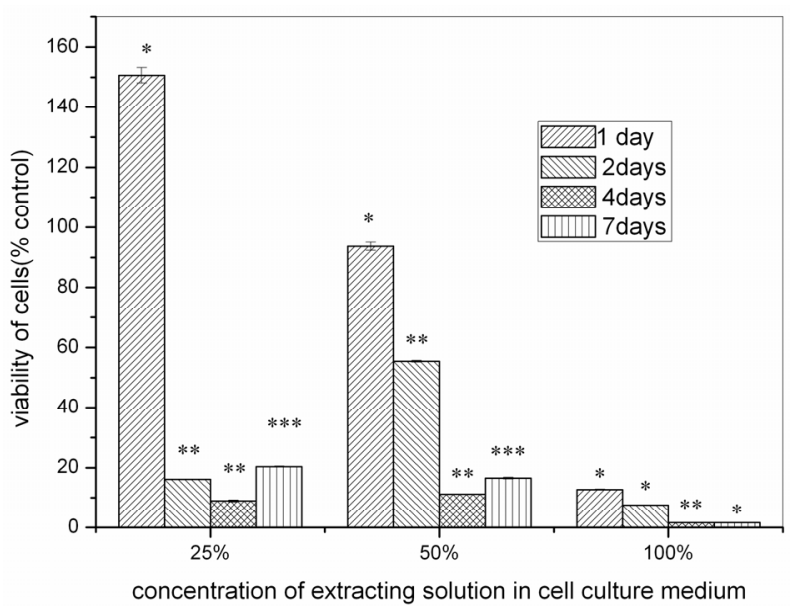

(b)

Figure 8. Indirect cytotoxicity evaluation of $\mathrm{LCH}$ sponges based on the viability of $\mathrm{HSF}$ cells (a) and HaCaT cells (b) " $p<0.05,{ }^{* * *} p<0.01,{ }^{* * *} p<0.001$ : significant deviations from the control at the respective extraction concentration and incubation time.

grade of $0-1$ for the $\mathrm{HaCaT}$ cells. By treatment with $100 \%$ LCH extraction, only approximately $15 \%$ cells showed viable phenomena by MTT assay.

Chitosan and its derivatives exhibit outstanding bioactive properties, whereas they have been reported to possess distinct toxic effects, as red blood cell lysis or cell growth inhibition [22]. In this experiment, LCH sponges were prepared for the potential use of wound dressing, so $\mathrm{HaCaT}$ and HSF were used as referenced cell lines to evaluate their potential cytotoxic effects. The results obtained indicate that LCH sponges exhibit bio-safety at lower concentration (25\%) during short time ( 1 day). The sponges prepared in our experiment are even less toxic than chitosan 1130 which has high molecular weight [23]. However, highly concentrated extraction shows a serious toxic effect on both HSF and HaCaT cells. HSF cells are much more sensitive to materials toxicity than $\mathrm{HaCaT}$ 
cells. This is probably due to the differentiated nature of these two cells. Cationic polymers have been known to be cytotoxic materials, however the mechanism has not been fully understood. There is a general acceptance that the interaction between the positively charged chitosan polymers and the negatively charged cell membrane destabilizes the cells structure, resulting in the rupture of cell membrane followed by cell death [24,25]. In our experiment, we can believe that the cytotoxic effect is partly originated by the increased acidity caused by the degradation of the lactate-modified chitosan sponges.

As we mentioned above that the sponges prepared in our experiment are a potential skin wound dressing. Usually, there is only one side of sponges will exposure to a skin wound in clinic application which is different from our cytotoxic test. In the case of immersion in extraction medium, the sponges hydrolyzed much faster than clinical application condition, resulting in significant increasing in concentration and cyctotoxicity. Once $\mathrm{LCH}$ wound dressing is used clinically, the dramatic dependence of cyctotoxicity on the time and concentration will level off.

\subsubsection{In Vitro Release Studies}

In our research, the sponges are made of hydrophilic chitosan salts, the controlled release in this kind of system must take into account three components: matrix erosion, drug diffusion and the structure of the porous microenviroment [26]. So drug release is controlled by two processes: erosion of the matrix and diffusion of the drug. As many classical drug release model, the pores in the matrix are classified into accessible and isolated region [27]. In our experiments, for simplification purpose, the pore which drug molecule located can be idealized as a cylinder. In Figures 9(a) and (b), we show release curves for penicillin and erythromycin in sponges with different formulation, representing the effects of the drug properties and matrix microstructure on the release behavior from bulk-degrading polymer. The figures allow for a direct visualization that the drug release increases with the increasing of TBA amount in the matrix. As we disused above, when was below $20 \%$, increasing TBA led to larger pore in sponges which was much more accessible to solvent. In hydrophilic drug system, Initial burst release is not observed, and penicillin is released entirely within 80 hours. The drug release in $10 \%$ TBA system presents linear release curve indicating a quasi zero-order kinetics. The curves in penicillin release do not exhibit square root of time profile, suggesting the release behavior is governed by both diffusion and erosion process. Penicillin is hydrophilic drug which can form homogenous system with LCH solution, so the release of drug from the LCH sponges must be accompanied with matrix erosion. As shown in Figure 10(a), penicillin causes extensive wrinkling in the internal surface of the pore but without noticeable aggregate, demonstrating the good dispersion of drugs in matrix. At the same time, dissolution of matrix structure can be accelerated by the release of drug from the sponge network because the release of drug leaves an imperfection on the network, thereby weakening the microstructure of matrix. Compared to erythromycin system, penicillin exhibits faster release characteristics due to the association of the faster erosion of the matrix and drug dissolution.

Exponential Functions were used to the experimental data of in vitro release of erythromycin from sponges with various formulations. Good correlation coefficients $\left(\mathrm{R}^{2}=0.99\right.$ - 0.97) were obtained for each case. As hydrophobic drug, erythromycin failed to solute in the LCH solution, causing efficient phase separation in the polymer solution consequently. Unlike penicillin which is trapped within the polymer uniformly, erythromycin was adsorbed on the surface of matrix. As shown in Figure 10(b), drug solids aggregate and form circular shape on the surface of internal pores. These could responsible for the initial burst release of erythromycin (Figures 9(c) and (d)). Due to this kind of morphological characteristics, the drug release has very limited influence on the matrix microstructure. The erythromycin/LCH sponges are much more compact and stiffer than those of penicillin. In the experiments, we observed that the permeation of the PBS solution in this kind of matrix only led to a limited erosion. For the 5\% LCH drug release system, the release curves display typical diffusion-controlled release curves, indicating that the diffusion is the predominant mechanism of drug release. For the 7\% LCH drug release system, the action of erosion is no longer negligible and the curve profiles polynomial function characteristics. The LCH solution with concentration of $7 \%$ is too viscous to dissolve the erythromycin, leading to low drugloading in matrix. The results of these simulations lead us to believe that the balance between diffusion and erosion will title towards erosion under this condition.

\section{Conclusions}

Due to the presence of two functional groups chitosan was modified by lactic acid without using catalysts in our present experiments. The crystallinity of LCH decreases after modification because the side chains replace the $-\mathrm{NH}_{2}$ groups in $\mathrm{CH}$ and destroy the regularity of packing between $\mathrm{CH}$ chains. As a complementary means to XRD, ${ }^{13} \mathrm{C}$ NMR demonstrates that modification mainly happened on the amino group of $\mathrm{C} 2$ in $\mathrm{CH}$ structure. The results of ${ }^{13} \mathrm{C}$ NMR suggest that a drastic conformational change of $\mathrm{CH}$ might occur during the modification with lactic acid, which agrees well with the XRD findings. TEM images show that different types of freezing behavior and TBA concentration lead to entirely different 


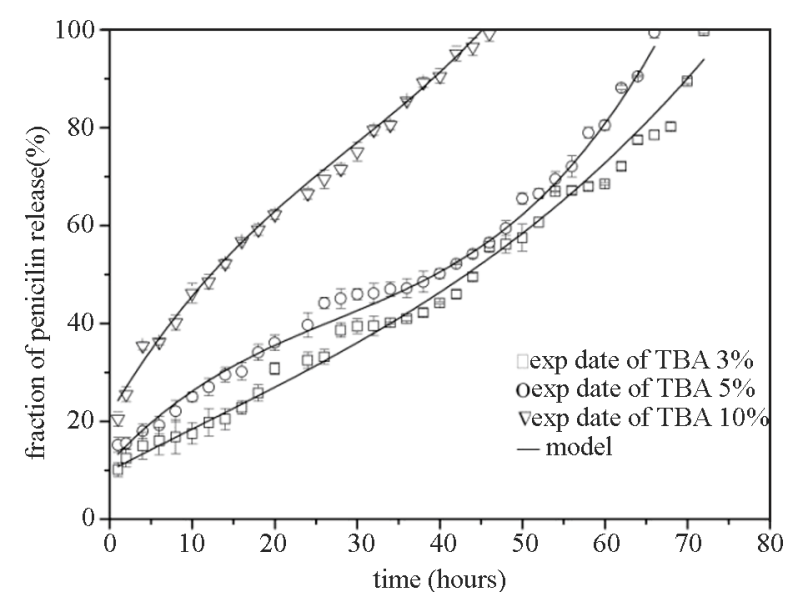

(a)

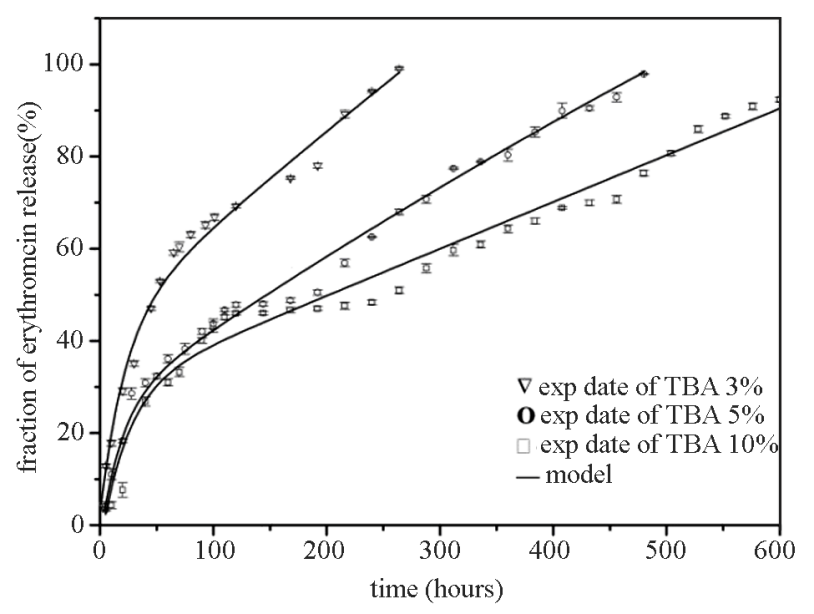

(c)

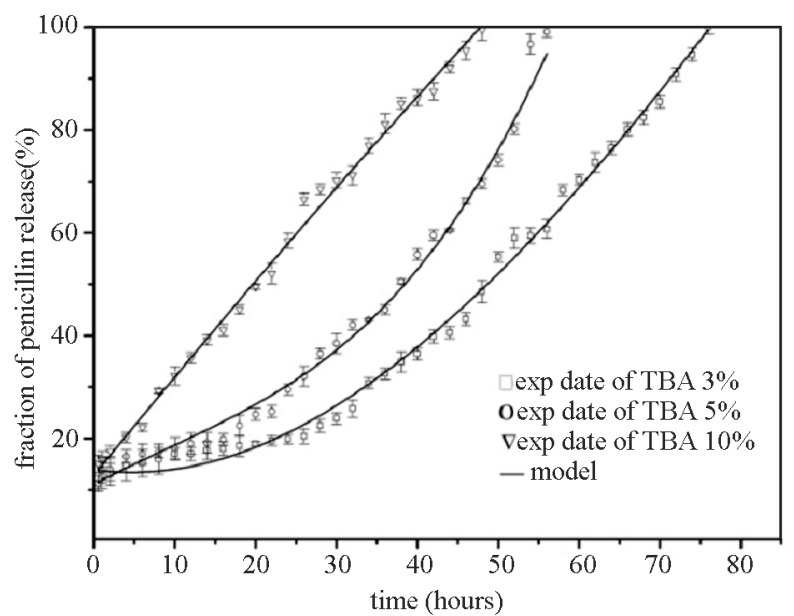

(b)

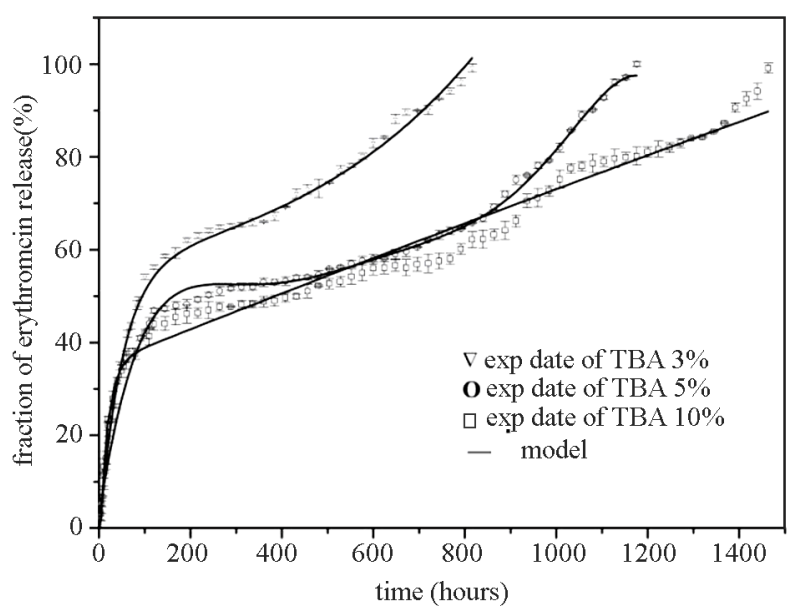

(d)

Figure 9. Cumulative release of penicillin and erythromycin from the sponges with various formulations. (a) penicillin from the $5 \% \mathrm{LCH}$; (b) penicillin from the $7 \% \mathrm{LCH}$;(c) erythromycin from the $5 \% \mathrm{LCH}$; (d) erythromycin from the $7 \% \mathrm{LCH}$. The dots represent data points and the solid lines are the corresponding release curves computed from the model.

micro-structure of sponges in our experiment. TBA does not exhibit a considerable inhibition effect on the ice crystallization, but it shows considerable influence on the crystal growth morphologies, possibly due to the presence of the specific weak hydrogen binding between TBA and water molecular.

As a potential wound dressing, the properties of water absorption behavior, cell viability and in vitro release are evaluated. Capillarity capacity parameter, $K s$, is introduced for the understanding of the structure-function relationship and the future development of LCH sponges in wound dressing. The water absorption depends on the LCH concentration more dramatically at higher TBA.

Indirect cyctotoxicity evaluation using HSF and Ha$\mathrm{CaT}$ cells indicates that the effect of $\mathrm{LCH}$ sponges on cyctotoxicity is time and concentration dependent. The results obtained indicate that $\mathrm{LCH}$ sponges exhibit biosafety at lower concentration (25\%) during short time (1 day) and much safer for HaCaT than HSF. However, highly concentrated extraction shows a serious toxic effect on both HSF and HaCaT cells using the soaking method in our experiments.

The in vitro release characteristic of hydrophilic and hydrophobic drug from the LCH sponges confirms that both the drug molecules diffusion and matrix erosion play important roles during the drug release. The in vitro release study of penicillin showed no burst effect, while the in vitro release study of erythromycin showed a clear burst effect with an initial fast release phase followed by a sustained release phase. Due to the hydrophilic properties, penicillin can accelerate the degradation of biodegradable carrier. As a result, the hydrophobic drug erythromycin release was significantly more prolonged than penicillin.

Wound healing is indeed a very complex process involving many complex steps as: the inflammatory phase, the proliferative phase and the remodel phase. In the paper, we just present a promising candidate in wound 


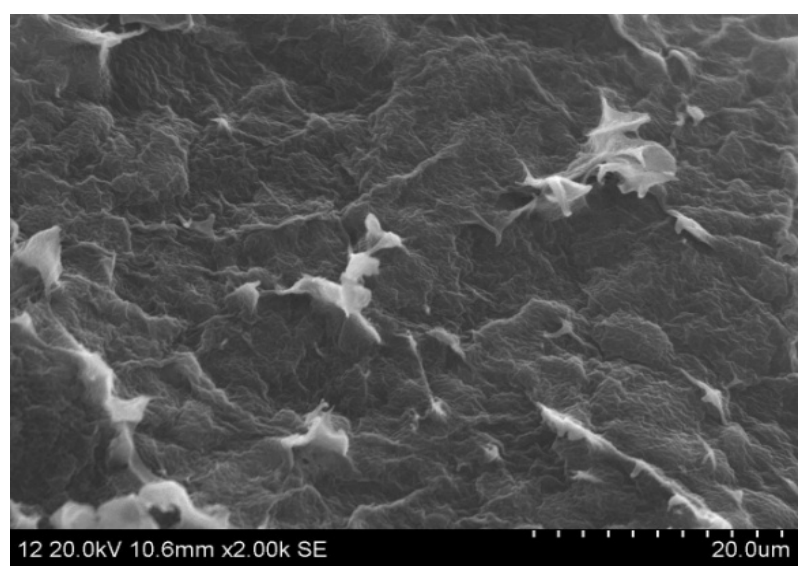

(a)

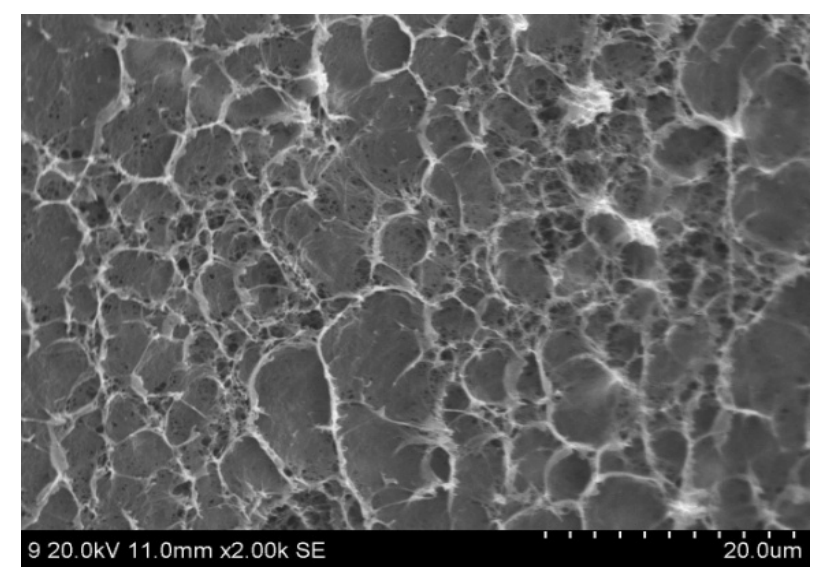

(b)

Figure 10. The internal surface of the sponge pores with penicillin (a) and erythromycin (b).

dressing. Further investigation such as animal and clinical test still needed to evaluate this kind of dressing in the future.

\section{Acknowledgements}

This research was supported by Major State Basic Research Development Program (973 Project No. 2012CB 933603), Science and technology research Foundation of Shenzhen Bureau of science and technology \& information (JC200903170498A).

\section{REFERENCES}

[1] S. W. Ali, M. Joshi and S. Rajendran, "Shape and Surface Charge of Chitosan Nanoparticles with Reference to Antimicrobial Activity," Advanced Science Letters, Vol. 3, No. 4, 2010, pp. 452-460.

[2] H. Hattori, Y. Amano and Y. Nogami, "Hemostasis for Severe Hemorrhage with Photocrosslinkable Chitosan Hydrogel and Calcium Alginate," Annals of Biomedical Engineering, Vol. 38, No. 12, 2010, pp. 3724-3732.

[3] M. R. Saboktakin, R. M. Tabatabaie, A. Maharramov and M. A. Ramazanov, "Synthesis and Characterization of Biodegradable Chitosan Beads as Nano-Carriers for Local Delivery of Satranidazole," Carbohydrate Polymers, Vol. 81, No. 3, 2010, pp. 726-731.

[4] B. Carreño-Gómez and R. Duncan, "Valuation of the Biological Properties of Soluble Chitosan and Chitosan Microspheres," International Journal of Pharmaceutics, Vol. 148, No. 2, 1997, pp. 231-240.

[5] R. A. A. Muzzarelli, "Modified Chitosans Carrying Sulfonic Acid Group," Carbohydrate Polymers, Vol. 19, No. 4, 1992, pp. 231-236.

[6] N. Saranya, A. Moorthi, S. Saravanan, M. P. Devi and N. Selvamurugan, "Chitosan and Its Derivatives for Gene Delivery," International Journal of Biological Macromolecules, Vol. 48, No. 2, 2011, pp. 234-238.

[7] D. W. Michael and H. H. K. Xu, "Osteoblastic Induction on Calcium Phosphate Cement-Chitosan Constructs for
Bone Tissue Engineering," The Journal of Biomedical Materials Research A, Vol. 94A, No. 1, 2010, pp. 223233.

[8] K. Kasraian and P. P. DeLuca, "Thermal Analysis of the Tertiary Butyl Alcohol-Water System and Its Implications on Freeze-Drying," Pharmaceutical Research, Vol. 12, No. 4, 1995, pp. 484-490.

[9] D. J. Drooge, W. L. Hinrichs and H. W. Frijlink, "Incorporation of Lipophilic Drugs in Sugar Glasses by Lyophilization Using a Mixture of Water and Tertiary Butyl Alcohol as Solvent," Journal of Pharmaceutical Sciences, Vol. 93, No. 3, 2004, pp. 713-725.

[10] P. L. Kang, S. J. Chang, I. Manousakas, C. W. Lee, C. H. Yao, F. H. Lin and S. M. Kuo, "Development and AsSessment of Hemostasis Chitosandressings," Carbohydrate Polymers, Vol. 85, No. 3, 2011, pp. 565-570.

[11] R. Jayakumar, M. Prabaharan, P. T. Sudheesh Kumar, S. V. Nair and H. Amura, "Biomaterials Based on Chitin and Chitosan in Wound Dressing," Biotechnology Advances, Vol. 29, No. 3, 2010, pp. 322-337.

[12] S. C. M. Fernandes, C. S. R. Freire, A. J. D. Silvestre, C. P. Neto and A. Gandini, "Novel Materials Based on Chitosan and Cellulose," Polymer International, Vol. 60, No. 6, 2011, pp. 875-882.

[13] Y. Q. Goh and C. P. Ooi, "Fabrication and Characterization of Porous Poly(L-Lactide) Scaffolds Using SolidLiquid Phase Separation," Journal of Materials Science: Materials in Medicine, Vol. 19, No. 6, 2008, pp. 2445 2452.

[14] H. Saito, R. Tabeta and K. Ogawa, "High-Resolution SolidState Carbon-13 NMR Study of Chitosan and Its Salts with Acids: Conformational Characterization of Polymorphs and Helical Structures as Viewed from the Conformation-Dependent Carbon-13 Chemical Shifts," Macromolecules, Vol. 20, No. 10, 1987, pp. 2424-2430.

[15] M. C. R. Symons, "Hydrogen-Bonded Solvent Systems," Covington and Jones, London, 1968.

[16] S. V. Madihallya and H. W. Matthew, "Porous Chitosan Scaffolds for Tissue Engineering, Structure and Properties of Bilayer Chitosan-Gelatin Scaffolds," Biomaterials, Vol. 20, No. 12, 1999, pp. 1133-1142. 
[17] J. S. Mao, L. G. Zhao, Y. J. Yin and K. D Yao, "Structure and Properties of Bilayer Chitosan-Gelatin Scaffolds," Biomaterials, Vol. 24, No. 6, 2003, pp. 1067-1074.

[18] R. J. Gummerson, C. Hall and W. D. Hoff, "The Suction Rate and the Sorptivity of Brick," Transactions and Journal of the British Ceramic Society, Vol. 80, No. 5, 1981, pp. 150-152.

[19] R. Mariarosa, D. Michele, G. Davide, G. Guia and M. Francesca, "Predicting the Initial Rate of Water Absorption in Clay Bricks," Construction and Building Materials, Vol. 23, No. 7, 2009, pp. 2623-2630.

[20] J. Bear, "Dynamics of Fluids in Porous Media," Elsevier, New York, 1972.

[21] USP XXII, NF XVII [S], "Toxicity classification in US Pharmacopeia," United States Pharmacopeial Convention, Inc., 1990, 2069.

[22] B. Carreño-Gómez and R. Duncan, "Evaluation of the Biological Properties of Soluble Chitosan and Chitosan Microspheres," International Journal of Pharmaceutics, Vol. 14, No. 2, 2013, pp. 4174-4184.

[23] C. Wiegand, D. Winte and U. C. Hipler, "Molecular-Weight-
Dependent Toxic Effects of Chitosans on the Human Keratinocyte Cell Line HaCaT," Skin Pharmacology and Physiology, Vol. 23, No. 3, 2010, pp. 164-170.

[24] D. M. Morgan, J. Clover and J. D. Pearson, "Effects of Synthetic Polycations on Leucine Incorporation, Lactate Dehydrogenase Release, and Morphology of Human Umbilical Vein Endothelial Cells," Journal of Cell Science, Vol. 91, No. 2, 1988, pp. 231-238.

[25] D. M. Morgan, V. L. Larvin and J. D. Pearson, "Biochemical Characterisation of Polycation-Induced Cytotoxicity to Human Vascular Endothelial Cells," Journal of Cell Science, Vol. 94, No. 3, 1989, pp. 553-559.

[26] V. Lemaire, J. Bélair and P. Hildgen, "Structural Modeling of Drug Release from Biodegradable Porous Matrices Based on a Combined Diffusion/Erosion Process," International Journal of Pharmaceutics, Vol. 258, No. 1-2, 2003, pp. 95-98.

[27] L. L. Lao, N. A. Peppas, F. Y. Boey and S. S. Venkatraman, "Modeling of Drug Release from Bulk-Degrading Polymers," International Journal of Pharmaceutics, Vol. 418, No. 3, 2011, pp. 28-41. 